\title{
Right mammary artery and saphenous vein non touch a combination for complete off pump revascularization in coronary surgery without touching the aorta
}

\author{
Federico J Benetti*1 and Natalia Scialacomo ${ }^{1}$ \\ ${ }^{1}$ Benetti Foundation, Alem 1846 Rosario Santa Fe Argentina
}

\begin{abstract}
The use of the right mammary as inflow with vein non touch or others conduits and the preservation of the LITA to LAD alone is another option for the patients that need coronary surgery in multivessels diseases without touching the aorta off pump.

Surgical Technique: After we finished the left internal mammary dissection we move the mammary retractor and dissected the right mammary artery with as much length as possible in complete sternotomy, and around 5 to $6 \mathrm{~cm}$ at the level of the 3 or 4 intercostal space in the Mini Sternotomy. The proximal part is prepared in beak flute and 3 sutures of 7-0 prolene are place in the the proximal and distal part. After we connected the vein depending of the number and situation of the potential anastomosis we add different piece of conduits either vein of right mammary or eventually a radial artery. After finished the proximal conduits we do first the LIMA to LAD anastomosis and complete the rest of the bypasses Results: Operative mortality 0\% Average hospital stay 59 hours MACE at 2 years $0 \%$.

Conclusion: More developed technique and the technology is needed to improve this operation and be able to reproduce in a big scale.
\end{abstract}

\section{Introduction}

The majority of the worldwide Coronary surgery typically requires exposure of the heart and its vessels through median sternotomy and cardiopulmonary bypass, making it one of the most invasive and traumatic aspects of open-chest surgery. Trying to decrease the risks of the CABG and its costs, in 1978 we popularized the Off Pump Coronary Artery Bypass Graft (OPCABG) [1,2] and expand the technique, addressing lesions of the circumflex system $(\mathrm{Cx})$ and applying it to diverse clinical scenarios. We tested several surgical approaches, such as full sternotomy, including left, anterolateral, posterolateral and right anterolateral thoracotomies, as well as partial sternotomy [3]. The video - assisted techniques in the nineties allowed, for the first time, to dissect the left internal thoracic artery (LITA) without opening the pleura cavity. The LITA was anastomosed to the left anterior descending (LAD) through a small left anterior thoracotomy. [4-6] and a new method for coronary bypass was created [7]. From 1996, a new series of technological developments allowed, widespread application of the OPCABG and MIDCAB techniques surgeons to perform high quality reproducible anastomoses and demonstrate in the great majority of reports, a decrease in postoperative morbidity. In 1997, we performed for the first time an ambulatory coronary bypass through a xiphoid lower sternotomy incision (MINI OPCABG) using 3D technology to assist in the operation [8], the low incidence of atherosclerosis of the IMA in contrast to frequent atherosclerosis of the LAD was proven histologically as well as biochemically [9]. As a number of North American teams have shown, this good patency rate of the LIMA to LAD seems to be maintained at long term, which is not the case with saphenous vein bypass grafts. We know that from more than 30 years [10]. In 1975 Tector describes the technique of end to side anastomosis and published results that suggested that the IMA is an excellent graft in most coronary bypass procedures $[11,12]$
Different variables of this original idea were described [13] and is some evidence that non touch the aorta off pump is the best option compared with conventional coronary surgery and stenting [14]. Harvesting the Saphenous Vein with the Non Touch technique conferred, at a mean time of 16 years, a significantly higher patency than the conventional technique that was still comparable to that of the LITA [15]. The used of the right mammary as inflow with vein non touch or others conduits and the preservation of the LITA to LAD alone is another option for the patients that need coronary surgery in multivessels diseases without touching the aorta off pump We know today that this option is the best alternative for patients with multivessels that need coronary surgery $[16,17]$ In this article we described our actual technique for perform this operation [18].

\section{Surgical technique}

After perform the sternotomy OPCAB or the Mini sternotomy MINI OPCAB we dissected the left internal mammary artery skeletonized, When is a complete sternotomy the dissection is with the more length as possible, if it is a Mini sternotomy only approximately $8 \mathrm{~cm}$ are necessary

After we finished the left internal mammary dissection we move the mammary retractor and dissected the right mammary artery with as

Correspondence to: Federico J Benetti, Benetti Foundation, Alem 1846 Rosario Santa Fe Argentina

Key words: OPCABG aorta, non touch Mini Opcabg, multiple bypasses, right mammary, inflow alternative coronary surgery

Received: March 02, 2017; Accepted: April 07, 2017; Published: April 10, 2017 
much length as possible in complete sternotomy, and around 5 to $6 \mathrm{~cm}$ at the level of the 3 or 4 intercostal space in the Mini Sternotomy We heparinized the patient with $3 \mathrm{mg} / \mathrm{kg}$.After we cut the right mammary at the level of the 4 intercostal space, the distal part is taking for the potential connection and ligated $2 \mathrm{~cm}$ approx. before the bifurcation in the sternotomy patients. The proximal part is prepared in beak flute and 3 sutures of 7-0 prolene are place in the the proximal and distal part and tied between the vein non touch and the right mammary and complete running is performing and tied in the midle of the lateral of the anastomosis. In the Mini sternotomy the procedure is the same Is important to leave between 5 to $6 \mathrm{~cm}$ of the proximal right mammary to perform a confortable anastomosis After we connected the vein depending of the number and situation of the potential anastomosis we can add different piece of conduits either vein of right mammary or eventually a radial artery After finished the proximal conduits we do first the LIMA to LAD anastomosis and complete the rest of the bypasses.

\section{Results}

From 2009 to 20168 patients 6 OPCABG and 2 MINI OPCABG were operate with this technique $30 \%$ females age $62-88$ average 69 Logistic Euro score preop risk 3,7 \% , Average bypass 2,7 per patient Operative mortality $0 \%$ Average hospital stay 59 hours MACE at 2 years $0 \%$.

\section{Conclusion}

This is another option for off pump coronary surgery without touching the aorta with saphenous with preservation of the fat, vein non touch. In this technique we preserve the LIMA to LAD anastomosis alone. The evidence of the patency of the vein non touch at 16 years open a new option to perform multiple bypasses with a potential equivalent results than the use of arterial conduits More developed of the technique and the technology is needed to improve this operation and be able to reproduce in a big scale.

\section{References}

1. Benetti FJ (1985) Direct coronary surgery with saphenous vein bypass without either cardiopulmonary bypass or cardiac arrest. J Cardiovascular Surg 3: 217-222.
2. Buffolo EJC Andrade J Succi, Leão LE, Gallucci C (1985) Direct myocardial revascularization without cardiopulmonary bypass. Thoracic Cardiovascular Surg 33: 26-29.

3. Benetti FJ, Naselli G, Wood M, Geffner L (1991) Direct myocardial revascularization without extracorporeal circulation. Experience in 700 patients 100: 312-316.

4. Benetti FJ, Ballester C, Barnia YA (1994) Uso de la Toracoscopía en cirugía coronaria para disección de la mamaria izquierda. La Prensa Médica Argentina 9: 81-87.

5. Benetti FJ, Ballester C (1995) Use of thoracoscopy and a minimal thoracotomy, in mammary-coronary bypass to left anterior descending artery, without extracorporeal circulation. Experience in 2 cases. J Cardiovascular Surg 36: 159-161.

6. Benetti FJ, Ballester C (1995) Coronary revascularization with the arterial conduits via a small thoracotomy and assisted by thoracoscopy, although without cardiopulmonary bypass. Coronary Revasc 4: 22-24

7. Federico Benetti : Method for coronary bypass United States Patent Patent N 5,888,247

8. Benetti F (1999) Minimally invasive coronary surgery (the xiphoid approach). Eur J Cardiothorac Surg 16 Suppl 2: S10-11. [Crossref]

9. Kobayashi H (1990) [The internal mammary artery as a graft material for coronary artery bypass surgery. Histopathologic and biochemical studies of its atherosclerotic changes]. Nihon Geka Gakkai Zasshi 91: 889-900. [Crossref]

10. Cron JP, Adolph WL, Alfandari JP, Baud F, Beuzelin JP, et al. (1986) [Follow-up angiography of 100 revascularizations of the anterior interventricular artery by the left internal mammary artery]. Arch Mal Coeur Vaiss 79: 1293-1300. [Crossref]

11. Tector AJ (1975) Letter: End-to-side vascular anastomosis. Ann Thorac Surg 19: 110 111. [Crossref]

12. Tector AJ, Davis L, Gabriel R, Gale H, Singh H, et al. (1976) Experience with internal mammary artery grafts in 298 patients. Ann Thorac Surg 22: 515-519. [Crossref]

13. Prapas SN, Anagnostopoulos CE, Kotsis VN, Stavropoulos GP, Sidiropoulos AV, et al (2002) A new pattern for using both thoracic arteries to revascularize the entire heart: the pi-graft. Ann Thorac Surg 73: 1990-1992. [Crossref]

14. Arrigoni SC et alOff-pump no-touch technique: 3-year results compared with the SYNTAX trial. Interact Cardiovascular Thorac Surg 20: 601-604.

15. Samano N. et al. (2015) The no-touch saphenous vein for coronary artery bypass grafting maintains a patency, after 16 years, comparable to the left internal thoracic artery: A randomized trial. Thorac Cardiovasc Surg 150: 880-888.

16. Kowaleski M, et al. (2016) Risk of stroke with "no-touch"-As compared to conventional off -pump coronary artery bypass grafting . An update meta -analysis of observational b studies. Int J Cardiol 222: 769-771.

17. Zhao, et al. (2017) Coronary artery Bypass grafting with and without Manipulation of the Ascending Aorta: A Network Metanalysis. J Am Coll of Cardiol 69: 924-936.

Copyright: $\odot 2017$ Benetti FJ. This is an open-access article distributed under the terms of the Creative Commons Attribution License, which permits unrestricted use, distribution, and reproduction in any medium, provided the original author and source are credited. 